\title{
EREBEA
}

Revista de Humanidades

y Ciencias Sociales

NúM. 7 (2017), pp. 127-152

ISSN: 0214-0691

\section{INTERCAMBIOS EPISTOLARES ENTRE JOHN KNOX Y TEOdoro DE BEZA: LA CONSOLIDACIÓN DEL EJE CALVINISTA ESCOCIA-GINEBRA}

\author{
Rocío G. Sumillera ${ }^{1}$ \\ Universidad de Granada \\ Pablo Toribio ${ }^{2}$ \\ ILC, CSIC, Madrid
}

RESUMEN

Como dirigentes de los movimientos reformistas de corte calvinista, el papel jugado por John Knox y Teodoro de Beza en Escocia y Ginebra, respectivamente, es crucial para entender la estructuración y organización de un movimiento religioso de reforma más allá de fronteras y políticas nacionales. Una selección de casi una veintena de cartas escritas en latín (aquí traducidas al castellano) enviadas a lo largo de dos décadas (entre 1561 y 1582) constituye el material a partir del que considerar el progreso de la causa calvinista en Escocia en particular, y en Gran Bretańa en general, según los relatos que los agentes principales de la misma compartían a través de cartas.

\section{Palabras Clave}

Knox; Beza; calvinismo, Ginebra; correspondencia.

Fecha de recepción: 10 de mayo de 2017 Fecha de aceptación: 11 de nov. de 2017

\section{Abstract}

As leaders of Calvinist movements of reform, the role played by John Knox and Théodore de Bèze in Scotland and Geneva, respectively, becomes crucial to understand the structure and organisation of a religious movement of reform that crosses political, i.e. national, borders. A selection of circa twenty letters originally written in Latin (and here translated into Spanish) and sent over a two-decade period (15611582) constitutes the material from which to analyse the progress of the Calvinist cause in Scotland in particular, and in Great Britain in general.

\section{KEYWORDS}

Knox; Beza; Calvinism; Geneva; correspondence.

1 Agradece la financiación recibida por el Proyecto Precompetitivo de la Universidad de Granada 'Protestantismo y rebelión política en la edad moderna' (PP2016-PJI02) para la realización de este artículo.

2 Ha trabajado en este artículo como miembro del Proyecto del MINECO "Recepción, transmisión y tradición de la Biblia en griego y latín" (FFI2014-51910-P). 

Desde que en el año 1960 la editorial Librairie Droz publicara a cargo de Fernand Auber y Henri Meylan el primer volumen de la correspondencia editada de Teodoro de Beza (1519-1605), el que comprende el periodo 1539-1555, llevan aparecidos, hasta el momento, un total de 42 tomos $^{3}$. Esta empresa de edición de la correspondencia de una figura tan crucial en la historia de la Reforma Protestante como fue Beza, pone a disposición del investigador una ingente cantidad de material acerca de alguien que fue mucho más que el mero sucesor de Calvino en Ginebra, y que arroja luz sobre las muchas facetas de un personaje fascinante que, además de reformador, fue un diplomático, un líder político, un profesor, un pastor y un poeta que mantuvo un rico y abundante intercambio epistolar con los más diversos correspondientes repartidos por toda la geografía europea. Uno de ellos no fue otro que el escocés John Knox (c. 1514-1572), líder de la Reforma en Escocia, y correspondiente, previamente, de Calvino, al que conoció personalmente y en cuya Ginebra vivió como exiliado durante el reinado de María I de Inglaterra (1553-1558). Si por Knox hubiera sido, habría vivido en Ginebra mucho más tiempo del que finalmente lo hizo: aunque en agosto de 1554 Knox marchó a Ginebra con la intención de asentarse en la ciudad, ante la petición de la comunidad de ingleses exiliados en Frankfurt para que se convirtiera en uno de sus pastores, y con Calvino presionándole para que la aceptase, al final se trasladó a la ciudad alemana en el mes de noviembre de ese año. A los ojos de Knox, según aseguraba en una carta a Anne Locke fechada el 9 de diciembre de 1556, Ginebra era "la escuela de Cristo más perfecta que haya existido jamás en la tierra desde los días de los Apóstoles": "En otros lugares, confieso que la palabra de Cristo es verdaderamente predicada, pero maneras y religión tan sinceramente reformadas, no he visto en ningún otro sitio" ${ }^{4}$. Su estancia en Ginebra fue probablemente el

3 El último, publicado en 2016, comprende los años 1601-1602. Théodore de Bèze, Correspondance de Théodore de Bèze, XLII vols. Genève: Droz, Travaux d'Humanisme et Renaissance, 1960-2016. De aquí en adelante, las referencias a tomos específicos de esta serie se harán indicando solamente el número de tomo, el nombre de los editores del mismo, y su fecha de publicación.

4 En inglés: "The maist perfyt schoole of Chryst that ever was in the erth since the dayis of the Apostillis. In other places, I confess Chryst to be trewlie preachit; but maneris and religioun so sinceirlie reformat, I have not yit sene in any uther place". J. Knox, The Works of John Knox, (15541558), vol. 4, D. Laing (ed.), Edimburgo: the Wodrow Society, 1895, p. 240. La traducción de este fragmento está tomada de José Luis Martínez-Dueñas Espejo y Rocío G. Sumillera, eds. John Knox. El primer toque de la trompeta contra el monstruoso gobierno de las mujeres. Tratado contra María 
periodo más feliz de la vida de Knox, y lo que allí vio lo quiso siempre para Escocia e Inglaterra; replicarlo se convertiría en la misión y la lucha de su vida, una que, en el momento de su muerte, entendió como un fracaso.

La correspondencia de Knox también ha sido editada, si bien la edición más completa de sus epístolas continúa siendo la realizada por David Laing en el siglo XIX 5 . Laing en efecto reúne aproximadamente un centenar de cartas escritas por Knox, muchas de las cuales habían sido recogidas antes, bien por el mismo Knox en alguna de sus publicaciones, bien en otras obras anteriores a la de Laing, como los seis volúmenes de David Calderwood (1575-1650) sobre la historia de la Iglesia de Escocia (no publicados hasta el siglo XIX) y el libro de Thomas $\mathrm{M}^{\prime} \mathrm{Crie}^{6}$. Con el tiempo, la colección de Laing, que también reúne epístolas que Laing encuentra en la British Library (entonces el British Museum), los National Archives (entonces los State Paper Office y luego los Public Record Office), ha sido enriquecida por nuevos hallazgos, algunos de los cuales sorprendentemente recientes ${ }^{7}$. La correspondencia de Knox, que en ocasiones ha sido estudiada específicamente en relación con sus cartas a mujeres ${ }^{8}$, ha sido además incluida, al menos de manera parcial, en colecciones de epístolas publicadas en el siglo XIX en torno a la correspondencia de los principales agentes de la Reforma Protestante en Gran Bretaña?.

Las páginas que siguen ofrecen al lector una selección de momentos en la correspondencia entre Beza y Knox que ilustran la naturaleza de su relación y su preocupación compartida respecto del avance de la Reforma Protestante tanto

Tudor y otras reinas de la edad moderna, Valencia: Tirant lo Blanch, 2016. p. 27.

5 J. Knox, The Works of John Knox, 6 vols., ed. David Laing. Edimburgo: the Wodrow Society, 1895.

6 David Calderwood, The History of the Kirk of Scotland, 8 vols, T. Thomson (ed.). Edimburgo: the Wodrow Society, 1842-9, y Th. M'Crie, The Life of John Knox, Edimburgo: J. Ogle, 1813, 2 vols.

7 Este es el caso de Jane Dawson and Lionel K. J. Glassey, "Some Unpublished Letters from John Knox to Christopher Goodman”, en The Scottish Historical Review, 84.218, part 2 (2005), pp. 166-201.

8 A. Daniel Frankforter, "Correspondence with Women: The Case of John Knox", en Journal of the Rocky Mountain Medieval and Renaissance Association, 6 (1985), pp. 159-172; Susan M. Felch, "'Deir Sister': The Letters of John Knox to Anne Vaughan Lok", en Renaissance and Reformation/ Renaissance et Reforme, 19.4 (1995), pp. 47-68.

9 H. Robinson (ed. y trad.), The Zurich Letters: Comprising the Correspondence of Several English Bishops and Others: With some of the Helvetian Reformers. During the Reign of Queen Elizabeth: 1558-1602. Cambridge: Cambridge University Press, 1846; H. Robinson (ed. y trad.), Original Letters Relative to the English Reformation: Written during the Reigns of King Henry VIII, King Edward VI, and Queen Mary: Chiefly from the Archives of Zurich. Cambridge: Cambridge University Press, 1846-1847; Matthew Parker, Correspondence of M. Parker, D.D., Archbishop of Canterbury: Comprising Letters Written by and to him, from A.D. 1535, to his Death, A.D. 1575, eds. John Bruce y Thomas Thomason Perowne. Cambridge: Cambridge University Press, 1853. 
en Escocia como en Inglaterra, así como la dirección que la misma iba tomando en ambas naciones. Aprovechan sus cartas para felicitarse por sus logros y consolarse en lo que percibían eran derrotas contra la fe verdadera. La peculiaridad de esta correspondencia es que ninguna de las cartas escritas por Knox a Beza ha sobrevivido, o, al menos, ha sido localizada, y que tan sólo una selección de cartas escritas por Beza y dirigidas a Knox ha llegado hasta nuestros días. Sabemos que algunas de entre las escritas por Beza a Knox se han perdido porque el propio Beza las menciona en epístolas a Heinrich Bullinger (1504-1575) que sí se conservan; en efecto con Bullinger, como se verá a continuación, Beza comparte en diversas ocasiones su inquietud acerca del futuro religioso de Inglaterra y Escocia. La correspondencia de Beza con Knox termina con la muerte de éste en 1572, pero sus referencias a Knox en sus cartas con otros correspondientes se prolongan hasta diez años más tarde, cuando le menciona en una carta dirigida a William Cecil (1520-1598), mano derecha de Isabel I. Sin embargo, es sobre todo con Peter Young (1544-1628), tutor de Jacobo VI de Escocia (y posteriormente del príncipe Carlos) y embajador real, con quien Beza habla de Knox; a él le transmite el pésame por su fallecimiento y ante él ensalza su labor.

Los fragmentos citados a continuación, en traducción al castellano de originales en latín ${ }^{10}$, se han extraído de un total de diecisiete cartas que ponen de manifiesto la importancia de la comunicación entre Escocia y Ginebra (y, en menor grado, Zúrich) en el establecimiento, bajo la supervisión de Knox, de una iglesia Reformada en Escocia en consonancia con la línea doctrinal iniciada por Calvino. En este sentido, atestiguan la configuración de una disidencia religiosa entendida como una actividad de resistencia prolongada en el tiempo y coordinada a nivel internacional, que complica la mera oposición al catolicismo, pues ésta sobre todo confronta diferentes concepciones de iglesia reformada, contrastando, especialmente, el anglicanismo (y la institución de la Iglesia Anglicana) con la Reforma tal y como se entiende en Suiza.

Un tema ciertamente ineludible en la correspondencia de Beza acerca de Knox y la causa en Inglaterra y Escocia, fue el impacto de la publicación en Ginebra de la obrita The first blast of the trumpet against the monstruous regiment of women (1558), que Knox publicó de manera anónima, y que luego confesó suya. La publicación, en extremo crítica con el reinado de María I de Inglaterra y María de Guisa en Escocia, pero también con el hecho en sí de que las mujeres pudiesen reinar, produjo un gran revuelo en ambos países que se prolongó durante el reinado de las sucesoras de ambas, a saber, Isabel I y María Estuardo, respectivamente. Isabel I jamás perdonó The first blast a Knox por haberla escrito, ni a Calvino por haber permitido la publicación de la obra bajo su atento mandato. Beza se refiere a ella en diversas cartas, por ejemplo en la que le escribe a Calvino desde Lausanne

10 Todas las traducciones del latín han sido realizadas por Pablo Toribio. 
el 24 de noviembre de 1557 (Carta 118), donde, si bien reconoce que Knox libró un "gran combate", de él también dice lo siguiente: "[de Knox] no puedo aprobar nada más que su intención. Pues defiende una causa excelente de la peor manera, y no se deja guiar por ningún consejo" ${ }^{11}$. Incluso en un año tan aparentemente lejano como 1582, Beza le escribe a William Cecil el 10 de octubre (Carta 1550), volviendo sobre el tema del libro de Knox y de cómo Calvino en ese momento se posicionó en contra de sus contenidos y reprendió a Knox por ello:

También me acuerdo de que en aquellos infelices tiempos de María publicó aquí un librito cierto paisano vuestro, que más tarde molestó a la majestad de la muy serena y piadosa reina. Pero en cuanto se dio a conocer este librito, consta que fue tanto condenado por el juicio de esta iglesia como suprimido por la autoridad del magistrado. [...] [E]sa cierta divergencia en ritos indiferentes y el consiguiente desacuerdo con nuestro criterio a la hora de establecer el gobierno eclesiástico no deben dividir unos ánimos que están absolutamente de acuerdo en el consenso de la doctrina en $\operatorname{si}^{12}$.

A pesar de no ser ajeno a las ideas de Knox acerca de la legitimidad de una rebelión contra el monarca, Calvino no anticipó jamás una publicación como The first blast. A principios de 1554 Knox visitó a Calvino en Ginebra, y luego a Bullinger en Zúrich con el propósito de hacerles a ambos exactamente las mismas cuatro preguntas. La primera tenía que ver con la autoridad política de un menor, un asunto claramente a propósito del reinado de Eduardo VI; la segunda era si una mujer podía gobernar y transferir sus derechos como monarca a su esposo; en tercer lugar preguntó si se le debía obediencia a los soberanos idólatras, y si las autoridades y magistrados menores podían resistirse al mandato real, y, en último lugar, si el resto de los súbditos podían unirse a la nobleza en caso de que ésta decidiera resistirse al mandato de un monarca idólatra. Calvino respondió a estas delicadas cuestiones de forma prudente y oralmente; Bullinger fue igual de pru-

11 Tomo II, 1556-1558, eds. Fernand Auber, Alain Dufour, Henri Meylan, Hippolyte Aubert, 1962, p. 127: "Si me velint nostri secum implicare, quod tamen puto non esse facturos, longe aliud consilium capiam, quam is cui tantum fuit certaminis, de quo ad me scripsisti, in quo nihil habeo, praeter unum scopum, quod possim probare. Nam optimam caussam tuetur pessime, neque ullis consiliis regi se patitur".

12 Tomo XXIII, 1582, eds. Alain Dufour, Hervé Genton, Béatrice Nicollier-De Weck, Hippolyte Aubert, 2001, p. 190-191: "Memini quoque infelicibus illis Marianis temporibus editum hic libellum a peregrino quodam vestrate, qui postea serenissimam pientissimae Reginae Majestatem offenderit. Sed cum libellum simul atque innotuit, et hujus Ecclesiae judicio et nostri Magistratus auctoritate, damnatum et suppressum fuisse constat. Illa denique nonnulla rituum adiaforon diversitas, atque adeo nostrarum in ecclesiastica constituenda gubernatione sententiarum repugnantia, absit ut animos in ipsius doctrinae consensu plane consentientes scindat". 
dente y probablemente más impreciso que Calvino, quizá porque sus respuestas fueron por escrito. De hecho, Bullinger remitió a Calvino su "An answer given to a certain Scotsman, in reply to some questions concerning the kingdom of Scotland and England" (Respuesta dada a cierto escocés en réplica a unas preguntas relativas a los reinos de Escocia y de Inglaterra) como anexo a una carta ${ }^{13}$. Ninguno de los dos tenía el menor interés en apoyar rebeliones o actos subversivos contra la autoridad real. Calvino afirmó que no existía justificación alguna para que los súbditos resistieran de forma violenta el mandato de su rey, aun siendo éste un idólatra o una mujer, pues si bien iba contra natura el que una mujer ostentase poder y se convirtiese en reina, justa o tirana sus súbditos debían obedecerla. Bullinger, por su parte, afirmó que si bien según las leyes temporales una soberana no debe encontrar oposición, por las leyes de la naturaleza y de Dios, una mujer no debería ni podría reinar. Su recomendación era no interferir en asuntos de sucesión al trono, y en todo caso, decía, había de considerarse cada caso de forma individual, dada la dificultad de la pregunta y lo complicado del asunto de la legitimidad de la resistencia. Knox interpretó las palabras de Bullinger de forma optimista, entendiendo que no rechazaba la resistencia por completo ${ }^{14}$.

Bullinger y Beza de hecho se escriben cartas en las que comentan el progreso de su causa en la isla de Gran Bretańa; de manera inevitable mencionan a Knox, y se llegan a enviar cartas (originales, no copias) escritas por el mismo Knox, como ya lo hiciera antes Bullinger con Calvino. Así, en una carta fechada el 6 de noviembre de 1565 y enviada desde Ginebra (Carta 431), Beza le remite a Bullinger aquella que le había escrito Knox (ahora perdida, como todas las demás de Knox a Beza) y sobre la que en la suya propia dice lo siguiente:

Te envío la carta del doctor Knox, ministro principal de los escoceses, por la que podrás enterarte de cuántos tumultos ocasiona allí también Satán. Has oído sin duda qué precaria es la situación en Inglaterra: hay muy pocos pastores y muchos mercenarios sin formación alguna; no se cuenta con ninguna organización de las costumbres; no existe ninguna disciplina eclesiástica. Entre tanto se discute sobre birretes y ropas de lino como si fueran las cuestiones más altas de la religión, no sólo con la connivencia de algunos obispos, sino

13 H. Bullinger, "Reply to Knox in an enclosure in a letter to John Calvin", Zúrich, 26 de marzo de 1554, en Robinson, Original Letters Relative to the English Reformation: Written during the Reigns of King Henry VIII, King Edward VI, and Queen Mary: Chiefly from the Archives of Zurich, Vol. 1, ed. y trad. Hastings Robinson. Cambridge: Cambridge University Press, 1847, vol. 1, pp. 745-747.

14 Para más información sobre la relación de ambos, consúltese J. H. Burns, "Knox and Bullinger”, en Scottish Historical Review, 34 (1955), pp. 90-91. 
incluso con la exhortación de la reina [Isabel I] a eso mismo, algo sobre lo que te he escrito también antes ${ }^{15}$.

A esta misiva Bullinger responde desde Zúrich el 28 de ese mes (Carta 436), devolviéndole además la carta de Knox ("Te reenvío la carta que el doctor Knox te envió desde Escocia y te doy muchas gracias por ella" ${ }^{16}$ y comentando lo siguiente acerca de las disputas superficiales, casi ornamentales, sobre las vestimentas litúrgicas a las que se refería Beza anteriormente:

Cuando vivía el doctor Mártir [Pierre Martyr] todavía estaba en auge en Inglaterra esa disputa sobre ropas y birretes. Y sé que escribió una y otra vez a los hermanos su parecer sobre esa cuestión, pero en vano. Siempre ha causado mucho mal a la Iglesia la disensión de los ministros, tanto sobre asuntos serios como sobre minucias. Es menester rogar al Señor para que ponga fin Él mismo a esas disputas. Si sabes qué ocurre entre los escoceses y los ingleses en esa desgraciada guerra que han emprendido, te ruego que me lo cuentes ${ }^{17}$.

Beza inaugura el primer día del año de 1566 con una carta de respuesta a Bullinger (Carta 441) en la que, tras su firma, en la posdata, anota: "En Escocia tengo entendido que la situación es muy lamentable, pues la reina de Inglaterra ha desposeído a los nuestros del modo más vergonzoso" ${ }^{18}$. Con este escueto comentario Beza se refiere al hecho de que, después de que María Estuardo adoptara medidas a favor de los católicos, algunos lores escoceses se levantaron contra ella y finalmente se refugiaron en Inglaterra en agosto de 1565; sin embargo, pronto se vio que el favor y apoyo de Isabel I con respecto a ellos era mucho menor del

15 Tomo VI, 1565. eds. Alain Dufour, Alexandre Henseler, Henri Meylan, Hippolyte Aubert. 1970, p. 197: "Mitto ad te D. Cnoxi primarii Scotorum ministri literas, ex quibus quantopere illic quoque Satan tumultuetur cognosces. In Anglia audivisti procul dubio quam miser sit status. Paucissimi sunt pastores, et plerique mercenarii penitus indocti. Morum ratio nulla habetur. Ecclesiastica disciplina nulla est. Interim de quadratis pileis et lineis vestibus ut de summa religionis certatur, quibusdam episcopis non modo conniventibus, sed etiam Reginam ad hoc ipsum hortantibus, qua de re jam antea etiam $\|$ ad te scripsi".

16 Tomo VI, 1565, p. 210: "D. Cnoxi literas ad te e Scotia missas remitto et maximas tibi gratias ago".

17 Tomo VI, 1565, p. 210: "Vivente D. Martyre adhuc viguit illa in Anglia vestiaria et pilearis concertatio. Ac scio illum semel et iterum ea de re suum ad fratres scripsisse judicium, sed frustra. Sempter || nocuit ministrorum concertatio sive de rebus gravibus, sive minutis, Ecclesiae plurimum. Orandus est Dominus ut ipse certamina illa dirimat. Si scis quid fiat apud Scotos et Anglos, in coepto illo infelici bello, tu me edoceas oro".

18 Tomo VII, 1566, eds. Claire Chimelli, Alain Dufour, Henri Meylan, Mario Turchetti, Hippolyte Aubert, 1973, p. 18: "In Scotia audio tristissimum esse rerum statum, nostris a regina Angliae turpissime destitutis". 
esperado ${ }^{19}$. El 19 de junio de 1566, Beza volvía a escribir a Bullinger poniéndole al día del asunto inglés y de controversias varias que también llegaban a Escocia (Carta 476):

Sobre Inglaterra ojalá pudiera darte noticias más alegres. Han destituido allí a más de cuarenta ministros por negarse a suscribir ciertos mandatos regios. Si se tratase sólo de ropas y de ese tipo de pequeñeces, sería triste, sin duda, oír que por esas cosas se agitan allí tan agudas controversias, no por parte de neófitos, sino de quienes ya hace tiempo que habrían debido controlar toda esa situación y enseñar también a los demás, para que fuesen de verdad lo que dicen ser, a saber, obispos cristianos; con todo, les aconsejaría que tolerasen eso antes que abandonar las iglesias. Pero dado que esos mandatos contienen abusos manifiestos y un abierto desorden, no me sorprende que la gente de buena conciencia no haya podido dejarse atar por ese tipo de leyes. Te envío una copia del escrito que me ha enviado desde allí un amigo ${ }^{20}$, para que lo leas y para que consideres con diligencia si podemos ofrecer por nuestra parte algún remedio para tan gran calamidad. También yo querría escribir algo al doctor de Londres y al doctor Cooke ${ }^{21}$ sobre estas cosas, pero temo perjudicarlos más que serles de ayuda. Pues en cuanto se refiere a la propia reina, dado que no se ha dignado a mostrarme ni con una sola palabra que le ha agradado el regalo de mis Anotaciones ${ }^{22}$, deduzco de ello que poco va a gustarle nada de lo que salga de esta iglesia, demasiado áspera y severa, como ella suele repetir.

En Escocia, la otra reina — pues place a Dios que ahora casi todos los reinos estén regidos por mujeres - tuvo tanto poder como para hacer desenterrar el cadáver de aquel secretario italiano suyo, David [Riccio], asesinado por el rey y algunos nobles, y se ha preocupado de instalarlo en los propios sepulcros regios; y tras llevarlo a término, con admirable astucia ha restituido a sus dignidades a los exilados que estaban depuestos - con la sola excepción de los cuatro asesinos

19 R. B. Wernham, The New Cambridge Modern History. Counter-Reformation and Price Revolution, 1559-1610. Cambridge: Cambridge University Press, 1968, vol. III, pp. 224-225.

20 Probablemente se tratase de Advertisements partly for due order in the publique administration of common prayers and usinge the holy sacramentes, and partly for the apparrell of all persons ecclesiasticall del arzobispo Matthew Parker (1504-1575), impresos en marzo de 1566.

21 Respectivamente, el obispo de Londres, Edmund Grindal (1516/20-1583), y Anthony Cooke (1505/6-1576).

22 Beza dedica sus Annotationes (1565) a Isabel I, a quien insta a establecer en la iglesia de Inglaterra una disciplina eclesiástica similar a la de Ginebra. 
de David - y ha devuelto la religión a su estado anterior, algo que de otro modo creía ella que iba a hacer su marido. Pero qué prepara esa enemiga capital del evangelio no debe ser oscuro para nadie, y que por tanto, a no ser que el Señor ponga coto a Satanás, también sobre aquellas regiones se ciernen tiempos terribles ${ }^{23}$.

De nuevo en correspondencia con Bullinger, Beza vuelve a insistir en el anhelo de la adhesión de las iglesias de Inglaterra y Escocia a la doctrina de Ginebra en una carta enviada el 16 de julio de 1566 (Carta 484), en la que anima a Bullinger a un compromiso más activo en esta dirección:

\begin{abstract}
Ojalá las iglesias inglesas y escocesas se uniesen a la nuestra, con la que comparten confesión, mediante algún escrito público, y que con él también enviasen a su gente, para al menos obstaculizar los intentos de algunos; sobre ello he escrito al obispo de Londres e igualmente a Escocia, a nuestro querido Knox, con la mayor diligencia. Pero querría que también tú y todos vosotros, querido padre, procuraseis esto mismo con empeńo y por todos los medios entre nuestros amigos ${ }^{24}$.
\end{abstract}

23 Tomo VII, 1566, pp. 142-143: "De Anglia utinam tibi possem laetiora nuntiare. Exautorati sunt illic quadraginta et amplius ministri, quod regiis quibusdam mandatis subscribere recusarint. Si de vestibus duntaxat et ejusmodi quisquiliis ageretur, triste quidem esset audire de his rebus tam acres controversias illic moveri non a neophytis, sed ab iis quos jam pridem omnia ista tenere et alios etiam docuisse oportuit, ut revera essent quod dicuntur, vere Christiani videlicet episcopi. Suaderem tamen ut tolerarentur ista potius, quam desererentur Ecclesiae. Sed quum manifesti abusus et aperta $\dot{\alpha} \tau \alpha \hat{\xi} \dot{\imath} \alpha$ illis mandatis invehantur, non miror bonae conscientiae homines istiusmodi legibus astringi non potuisse. Mitto ad te exemplar ejus scripti quod illinc ab amico accepi, ut legas, et diligenter dispicias ecquid remedii tantae isti calamitati afferri a nobis possit. Velim quidem et ego libenter aliquid ad D. Londinensem et D. Cokum de his rebus scribere. Sed vereor ne noceam potius quam prosim. Nam quod ad Reginam ipsam attinet, quum ne verbo quidem dignata sit testari gratum sibi fuisse mearum annotationum munus, ex eo conjicio parum illi placiturum quicquid ex hac Ecclesia nimium, ut ipsa dictitare solet, aspera et severa, proficisceretur.

In Scotia, tantum potuit alia Regina (jam enim Deo placet omnia fere regna a mulieribus regi), ut sui illius Itali secretarii Davidis \| a Rege et proceribus aliquot interfecti cadaver effodiendum et regiis ipsis sepulchris inferendum curaverit, quod ubi peregisset, miro quodam astu revocatos exules suis dignitatibus (quatuor duntaxat exceptis Davidis interfectoribus) restituit, et religionem ad priorem statum revocavit, quod alioqui facturum esse maritum existimabat. Quid autem paret ipsa capitalis Evangelii hostis, nemini obscurum esse potest, ac proinde, nisi Dominus Satanam compescat, illis quoque regionibus horrendas tempestates imminere".

24 Tomo VII, 1566, p. 185: "Utinam Anglicanae et Scoticae Ecclesiae sese cum nostra communi confessione publico aliquo scripto conjungerent et suos eo etiam ad impediendos saltem quorundam conatus mitterent, qua de re ad Londinensem episcopum, itemque in Scotiam ad Cnoxum nostrum diligentissime scripsi. Sed velim te vosque adeo omnes, mi pater, id quoque sedulo modisque omnibus apud amicos curare". 
Meses después, el 3 de septiembre de ese mismo año, Beza vuelve a escribir a Bullinger tocando extensamente el "tema de Inglaterra" ("ad Anglicum negotium") (Carta 500), y recordando que Ginebra les ofreció refugio a muchos durante el reinado de María Tudor, con lo que el vínculo entre ambas comunidades es históricamente fuerte. Con Isabel I la Iglesia de Inglaterra, dice Beza, no es mucho mejor que la católica, pues afirma que el poder del Papado ahora queda transferido a la figura de la reina:

Nuestros desgraciados hermanos buscan consuelo, consejo y oraciones de las iglesias en cuya caridad se consolaron en el pasado y todavía tienen la esperanza de consolarse. Algunos son un poco enojosos, lo reconozco. Pero en tan grandes desgracias es difícil guardar la mesura, y dado que su intención es la mejor, creo que hay que perdonarles su importunidad. Por los sucesos que vas a oír contados uno a uno por nuestro hermano ${ }^{25}$ — de su relato ha dejado también aquí conmigo una copia—comprenderás que todavía no se ha expulsado de allí al papado, sino que más bien se ha traspasado a su regia majestad, y que ahora no se intenta otra cosa sino restituir poco a poco lo que de alguna manera se había reformado. Durante un tiempo pensé que se trataba solo de unos birretes y no sé qué cosas externas, pero después he entendido que la controversia es muy diferente, y ahora lo veo con claridad, no sin increíble dolor de mi alma, el cual desearía que fuera sólo y exclusivamente mío $^{26}$.

Beza procede entonces a describir en detalle las razones por las que decenas de ministros han sido destituidos, y de manera muy explícita establece una correspondencia entre las jerarquías católicas y las anglicanas:

En primer lugar, $[\ldots]$ los consideran aptos para servir [...] o para enseñar, $[\ldots]$, cuando esas funciones están vacantes, asignan según su antojo a éstos o aquéllos a las iglesias que les parece bien, tras

25 Posiblemente Percival Wiburn (1533/4-1606), que fue uno de los pastores de Londres destituidos.

26 Tomo VII, 1566, p. 223: "Miseri fratres consolationem, consilium, preces ab iis Ecclesiis petunt, quarum olim charitate sunt recreati, et nunc quoque se recreandos sperant. Morosuli sunt nonnulli, fateor. Sed in tantis miseriis difficile est modum tenere, et quum scopus illorum sit optimus, condonandam arbitror hanc importunitatem. Ex iis $\|$ quae sigillatim ex hoc nostro fratre audies, quorum etiam exemplar hic apud me reliquit, cognosces neque unquam illinc ejectum fuisse papatum, sed ad Regiam Majestatem potius translatum, neque nunc aliud captari quam ut sensim restituantur quae utcunque fuerant instaurata. Putavi aliquando de pileis tantum et nescio quibus externis agi; sed postea longe aliam esse controversiam intellexi, et nunc palam video, non sine incredibili animi dolore, qui utinam mihi uni proprius et peculiaris esset". 
entregarles la carta de titularidad a cambio de cierto pago y tomarles juramento de dos cosas: una, que están dispuestos a reconocer a su regia majestad como la principal cabeza de la iglesia de Inglaterra después de Cristo; otra, que seguirán las leyes del reino y sobre todo aquel ilustre 'libro de la reforma' y todos los ritos, de forma que no censuren nada de ellos. Si se pregunta sobre la disciplina eclesiástica, ¿cuál hay allí, si, del mismo modo que bajo el papado, en lugar de un cuerpo de presbíteros elegido legítimamente, tienen a sus deanes, cancilleres, archidiáconos y oficiales? Estos, según su antojo y como suele hacerse en el foro civil, aunque basándose en el derecho canónico, pronuncian la excomunión incluso por litigios de dinero y semejantes, y dicha sentencia después, como un juez a su asistente, se la transmite el señor obispo o su oficial al ministro para que la lea en la iglesia, y ésta tiene vigencia hasta que lo arreglen con un juez. Pues por lo general la causa de la absolución es la misma que la de la excomunión. ¡Y qué cerca están de la ley del celibato, pues tienen prohibido tomar esposa sin el permiso expreso de la reina y el consentimiento pacífico del señor obispo y de dos ciertos oficiales, o si las han tomado tienen prohibido mantenerlas en los colegios o dentro del recinto de las catedrales, como si fueran impuras, o bien para evitar el escándalo! ¿Y qué decir de que a los papistas no sólo se ha dejado el rédito de los beneficios, sino también las propias funciones eclesiásticas, con la única condición de que presten juramento a la reforma, de modo que por lo general nuestros piadosos hermanos están sometidos a hombres indoctos y muy hostiles enemigos en su corazón de la religión verdadera, y están obligados a sufrir su jurisdicción? [...] Y como si estas cosas, junto con algunas otras no mejores, no fuesen suficientes, he aquí que los poquitos doctores del puro evangelio pierden sus cargos o incluso se ven arrojados a la cárcel, a no ser que juren que van a aprobar absolutamente todas esas cosas, sin que sea posible decir nada en contra ni de palabra ni por escrito; y finalmente los devuelven con birretes cuadrados, collares, mantos, casullas y las demás cosas de ese tipo, convertidos en sacerdotes de Baal.

Y éste no es el fin de las desgracias, sino que se ha tomado también expresamente la precaución de que a su regia majestad le baste reunirse con el obispo de Canterbury para que en seguida quede establecido y sancionado cualquier cosa que le parezca bien imponer, cambiar o quitar en los ritos de la Iglesia.

Éste es, pues, el estado de las iglesias de Inglaterra, muy lamentable, según me parece, y tan absolutamente intolerable. Esas poquísimas 
personas nos piden un doble consejo: uno, de qué manera podría recordársele su función a la reina y los obispos; dos, qué les es lícito hacer entre tanto en buena conciencia ${ }^{27}$.

Beza está convencido de que Isabel I odiaba la iglesia de Ginebra, y que por ello, insiste como ya lo había hecho anteriormente, no le ha escrito agradeciéndole la dedicatoria y el envío de un ejemplar de sus Anotaciones: "por esa razón no se ha dignado comunicarme ni con la palabrita más pequeña que le hayan agradado las Anotaciones mías que le regalé" 28 . La publicación de la obra de Knox en efecto hizo flaco favor para suavizar las relaciones con Ginebra, como él mismo admite:

27 Tomo VII, 1566, pp. 223-224: "Primum, quum externa vocatio praeeunte justo doctrinae et morum examine, non ab uno aliquo, sed a fratrum saltem coetu facta sit Ecclesiastici ministerii veluti basis et fundamentum, quid turpius, quid immoderatius Ista episcoporum licentia, ut non vocatos, sed ultro accedentes pro arbitrio immatriculent; mox nullo assignato loco, tanquam idoneos vel ad inserviendum (ut vocant) vel ad docendum approbent, ac tandem, quum vacant ista ministeria, pro libito hos vel illos, tradita certo pretio scheda et accepto duabus de rebus jurejurando (una Regiam Majestatem pro supremo post Christum Anglicanae Ecclesiae capite agnituros, altera, leges Regni, et in primis praeclarum illum Reformationis librum ritusque omnes ita secuturos, ut nihil prorsus improbent) quibus libuit Ecclesiis assignent? Si de disciplina Ecclesiastica quaeritur, quaenam tandem illic est, ubi non aliter quam sub papatu, loco presbyterii legitime delecti, suos Decanos, Cancellarios, Archidiaconos, Officiales habent, qui pro arbitrio, et ut in foro civili fieri solet, ex jure tamen canonico, excommunicationem pronuntie[n]t, etiam ob pecuniarias et ejus generis lites, quam sententiam postea ut judex suo apparitori, sic Dominus episcopus vel ejus officialis ministro legendam in Ecclesia transmittat, tantisper scilicet valituram donec cum judice transegerint. Eadem enim est plerumque absolutionis quae excommunicationis ratio. Quantulum autem absunt a lege coelibatus, qui uxores sine expressa Reginae venia, et D. episcopi et duorum quorundam justitiariorum pacis assensu ducere, ductas autem vel in collegiis, vel intra cathedralium || Ecclesiarum septa, ut impuras nimirum, sive ut vitetur offendiculum, alere prohibentur? Quid quod papistis non tantum beneficiorum redditus, sed etiam ipsa Ecclesiastica munera relicta sunt, praestitum tantum reformationis servandae jurejurando, adeo ut plerisque et indoctis et verae religionis in corde infensissimis hostibus, pii fratres plerumque subsint, eorumque jurisdictionem subire teneantur? [...] Et quasi ista cum aliis quibusdam nihilo melioribus non sufficerent, ecce jam pauculi illi puri Evangelii doctores alii quidem exauthorantur, alii vero in carceres etiam detruduntur, nisi illa omnia se inviolabiliter approbaturos jurent, ut neque verbo neque scripto contradicere liceat; ac tandem etiam pileis quadratis, collipendiis, supelliciis, casulis et caeteris id genus, sacerdotes Baalis referant.

Neque hic est miseriarum finis. Sed illud quoque expresse cautum est, ut quicquid Regiae Majestati, adhibito vel solo Cantuariensi, in Ecclesiae ritibus instituere, mutare, tollere libuerit, firmum statim et ratum habeatur.

Hic est igitur Anglicanarum Ecclesiarum status valde, ut mihi videtur, miserabilis, atque adeo plane intolerabilis. Pauculi autem illi duplex consilium a nobis flagitant. Unum, qua tandem ratione Regina et episcopi possint officii admoneri, alterum quid ipsis interea bona conscientia liceat".

28 Tomo VII, 1566, p. 224: "Nam quod ad hanc Ecclesiam attinet velim scias ita esse illi Reginae exosam, ut propterea ne levissimo quidem verbo sibi gratum esse mearum annotationum munus significarit." 
La causa de este odio es doble: una, que nos mostramos demasiado severos y rígidos, y eso les disgusta especialmente a los que temen que se les reprenda; y dos, que hace tiempo, sin saberlo nosotros, cuando todavía vivía María, se publicaron dos libritos en lengua inglesa, uno en contra del gobierno de las mujeres, del doctor Knox, y otro sobre el poder del magistrado, del doctor Goodman ${ }^{29}$. Los dos nos disgustaron también a nosotros cuando supimos qué contenían, y por ello se prohibió venderlos. Pero ella, no obstante, mantiene la opinión que se ha formado ${ }^{30}$.

La propuesta de Beza a Bullinger sobre cómo proceder es sencilla: Beza sugiere que "se eligiese a un magistrado" de entre la comunidad de Zúrich "que marchase por esta misma razón a Inglaterra y buscase remedio a todos estos males ante la reina y los obispos" ${ }^{31}$. Califica una empresa de este tipo como algo "heroico, digno de vuestra ciudad y enormemente grato a Dios, [...] incluso aunque no tuviese todo el éxito que se espera" ${ }^{32}$. Añade, además, que si Ginebra puede aportar una carta de apoyo a tal iniciativa, no habría "ninguna demora". Beza está convencido de que el apoyo de comunidades extranjeras darían ánimos renovados a sus partidarios ingleses: "si ven que también iglesias de fuera se preocupan tanto por su salud, [puede que] cobren ánimos para insistirle con más fuerza a su regia majestad, hasta doblegarla" ${ }^{33}$. Beza sugiere a Rudolf Gwalter o Gwalther (1519-1586), eclesiástico de Zúrich, para tal función diplomática, que Beza califica como "la vía más adecuada", pues además, dice, "no supone tanto gasto ni esfuerzo": "Pero si no os agrada, por lo menos creo que habría que dirigir una carta seria y extensa

29 C. Goodman, How Superior Powers oght to be Obeyd of their Subiects and Wherin they may Lawfully by Gods Worde be Disobeyed and Resisted. Ginebra: John Crispin, 1558.

30 Tomo VII, 1566, p. 224: "Causa hujus odii duplex est, una quod nimium severi et rigidi habeamur, quod iis maxime displicet qui reprehendi metuunt, altera, quod olim, inscientibus tamen nobis, vivente adhuc Maria, editi sint duo libelli anglicano sermone, unus adversus foeminarum imperium a D. Cnoxo, alter de jure Magistratus a D. Gudmanno scriptus. Uterque, quum quid continerent intellexissemus, nobis quoque displicuit, ac proinde prohibitus est vaenire. Sed illa nihilominus conceptam opinionem fovet".

31 Tomo VII, 1566, p. 224: "Itaque, si dignam hanc causam esse statuis quae a vobis suscipiatur, haec commodissima et fratribus utilissima ratio esse videretur, ut Magistratus vestri, si non authoritate, saltem permissu vel conniventia, deligeretur cx vestro coetu qui, in Angliam hanc ipsam ob causam proficiscens, omnibus istis malis coram remedium apud Reginam et episcopos quaereret".

32 Tomo VII, 1566, p. 224: "Heroicum sane esset hoc factum, vestra civitate dignum, et Deo longe, ut arbitror, gratissimum, etiam si non succederet prorsus ex animi sententia".

33 Tomo VII, 1566, p. 225: "Omnes istos probabile est, si externis quoque Ecclesiis salutem suam tantae curae esse viderint, animum sumpturos ut apud Regiam Majestatem fortius instent, donec illam flexerint". 
tanto a su regia majestad como a los obispos, para que recuerden su función y su deber" ${ }^{34}$.

A finales de año, el 8 de diciembre de 1566, Beza vuelve a escribir a Bullinger (Carta 520) enviándole "copia de la muy extensa carta de Knox" (perdida, como todas), por medio de la que, dice, "conocerás toda la situación de Escocia”35. A esta adjunta la siguiente carta, fechada en St Andrews el 4 de septiembre de ese año, que los profesores y pastores escoceses envían a Beza como respuesta de la propuesta de éste a que la iglesia de Escocia suscribiese la Confession helvétique postérieure:

Salud y paz del Señor. Hemos leído hace poco tu carta, atentísimo pastor cristiano, enviada a nuestro muy querido hermano John $\mathrm{Knox}^{36}$, que sin duda nos ha afectado de diversas maneras. En efecto, lo que cuentas sobre que vuestra iglesia goza de una gran paz y tranquilidad nos ha llenado de alegría, como correspondía [...].

[C] uando leemos en la misma carta que tú y tus hermanos nos pedís insistentemente que aprobemos con nuestro voto vuestra confesión y sencilla exposición de la fe ortodoxa y de los dogmas católicos de la sincera religión cristiana, publicada el pasado mes de marzo por los ministros de las iglesias de Suiza-Zúrich, Berna, Schaffhausen, San Galo, Coira (Chur)_ _y entre los confederados Mulhouse y Biel, a los que se han sumado los ministros de la iglesia de Ginebra, en ello reconocemos y proclamamos la enorme humanidad hacia nosotros, tuya y de los tuyos, pues tenéis en tanto a los escoceses-pueblo que en los últimos rincones de la tierra sirve a Dios con una religión sincera- como para juzgar que por su acuerdo se añade mucha luz y brillo a la religión cristiana, que habéis abarcado en ese librito.

Por ello, para que nuestro empeño no dejase de corresponder a tan gran humanidad y tan justa petición, en cuanto vimos tu carta salimos volando todos los de los pueblos vecinos a Saint Andrews, la ciudad más floreciente de Escocia en letras divinas y humanas. Allí, con toda la rapidez que pudimos, inspeccionamos el libro, valoramos cada uno de sus capítulos, no dejamos nada sin examinar y analizamos con diligencia todo lo relativo a Dios, las leyes sagradas y los

34 Tomo VII, 1566, p. 225: "Haec una via est promptissima, quantum ego quidem judico, nec ita magni sumptus aut laboris. Sin vero hoc non placet, saltem literas graviter et copiose scribendas tum ad Regiam Majestatem tum ad episcopos arbitror, ut sui muneris et officii commonefiant, quum praesertim illos videas literis tuis contra voluntatem tuam ad augendum hoc malum abuti".

35 Tomo VII, 1566, p. 287: "Mitto ad te Cnoxii literarum copiosissimarum exemplar ex quibus totum Scotiae statum cognosces".

36 Esta carta, probablemente datada a finales de junio, también se ha perdido. 
ritos de la Iglesia. Y no puede decirse cuánta alegría recibimos por su causa, al advertir claramente que en vuestro librito se explica con la mejor fe, de forma santa, piadosa y del todo divina, y además con brevedad, lo que nosotros hemos enseñado todos estos ocho años en los templos, en la escuela y en el púlpito, y todavía enseñamos, gracias a Dios. Así pues, nos vemos obligados a asumir su patrocinio, porque nos apremia tanto la conciencia como nuestro deber, y no sólo aprobamos, sino que incluso alabamos grandemente todos sus capítulos y todas sus opiniones. Pues aquel librito se apoya por completo en las Escrituras Sagradas, que profesamos y que estamos dispuestos a proteger con peligro de nuestra vida e incluso con el derramamiento de nuestra sangre. Pusimos nuestra firma todos los que pudimos asistir pese a la estrechez del tiempo concedido, y lo rubricamos con el sello oficial de esta universidad.

[...]

Te hemos escrito esta carta con la mayor brevedad, para adaptarnos a la estrechez del tiempo. Pero te rogamos con gran solicitud que no permitas que decaiga la costumbre de tu amistad hacia nosotros, ya comenzada. Si lo haces con empeño, nos esforzaremos por devolverte semejante favor ${ }^{37}$.

37 Tomo VII, 1566, pp. 346-347: “S. et pacem a Domino. Legimus nuper literas tuas, christiane pastor vigilantissime, ad charissimum nobis fratrem Johannem Knoxum missas, quae profecto varie nos affecerunt. Quod enim Ecclesias vestras et pace et tranquillitate magna frui narras, perjucundum nobis fuit, ut debuit. [...]

Quum vero ex eadem epistola intelleximus, te tuosque fratres a nobis enixe postulare, ut Confessionem vestram et expositionem simplicem orthodoxae fidei, et dogmatum catholicorum syncerae religionis christianae, concorditer ab Ecclesiae ministris, qui sunt in Helvetia, Tiguri, Bernae, Scafhusiae, Sangalli, Curiae Rhetorum, et apud confoederatos, Mulhusii, item et Biennae, quibus adjunxerunt se et Genevensis Ecclesiae ministri, mense Martio recens editam, nostris suffragiis comprobaremus, in eo summam erga nos humanitatem tuam, tuorumque ingenue agnoscimus et praedicamus, qui Scotos, gentem in ultimis terrae angulis Domino servientem cultu religionis syncero, tanti aestimatis, ut eorum consensione judicetis ad religionem christianam, quam eo libello estis complexi, posse multum lucis et splendoris accedere.

Quare ne studia nostra humanitati tantae et tam aequae postulationi deessent, simul ac tuas vidimus literas, cuncti e proximis quibusque oppidis Andreopolim convolavimus, urbem literis divinis humanisque in Scotia florentissimam. Ibi, quanta fieri potuit celeritate, librum eum inspeximus, capita ejus singula expendimus, nihil inexploratum praetermisimus, omnia de Deo, sacris legibus ritibusque Ecclesiae diligenter excussimus. Dici autem non potest, quantum ex ea opera laetitiae ceperimus, cum perspicue cerneremus, libello vestro, fide optima, sancte, pie, planeque divinitus, idque breviter explicari, quicquid nos $\|$ in templis, in scholis et in suggestu his octo annis perpetuis docuimus, et adhuc (Deo est gratia) docemus. Ejus ergo patrocinium suscipere, tum conscientia urgente, tum officio, penitus cogimur, ac omnia ejus capita omnesque sententias, non solum adprobare, sed etiam magnopere laudare. Nititur enim libellus ille, prorsus literis sacris, quas et profitemur, et capitis periculo, vel etiam sanguinis profusione, parati sumus tueri. Subscripsimus 
La siguiente carta (Carta 677), fechada el 3 de junio de 1569, es la primera que se conserva de Beza específicamente a Knox, al que saluda como "restaurador del evangelio entre los escoceses, hermano y venerable compañero de sacerdocio" ("Joanni Cnoxo, Evangelii Dei apud Scotos instauratori, fratri et symmystae observando"), y al que agradece la adhesión de Escocia a la Confession helvétique postérieure, confirmada en el documento anterior:

Te deseo gracia y paz, querido hermano, y a todas vuestras santas iglesias de parte de Dios, Padre de nuestro Señor Jesucristo, al que también yo doy las gracias continuamente tanto por los grandes beneficios que os ha destinado como por vuestra singular constancia y fortaleza de ánimo en la tarea de establecer su culto.

Por lo demás, cuando se me entregó aquel honroso y verdaderamente cristiano testimonio de vuestra universidad, con el que habéis abrazado la confesión de nuestras iglesias, algunos meses después os comuniqué, a ti privadamente y a otros hermanos por $\operatorname{carta}^{38}$, qué grata y qué gozosa fue para todos nosotros y para ellos, y en particular para los hermanos de Zúrich, esa armonía en el Señor que habéis mostrado en todos los puntos con todos nosotros, que confiamos que será eterna y que se mantendrá firme ante las propias puertas del infierno.

En cuanto a que desde entonces no hayas recibido de mí ninguna carta, no querría, querido hermano, que lo atribuyeses a desprecio o negligencia, ni siquiera a mis ocupaciones, sino en parte a la escasez de mensajeros- pues la verdad es que no encontré a ninguno adecuado- $-\mathrm{y}$ en parte también a las continuas tempestades de estos tiempos, porque, si bien gracias a cierto beneficio singular de Dios óptimo máximo esta ciudad todavía no se ha visto afectada por ellas, sin embargo, están muy cerca de nosotros, como sabes [...].

Pero de nuestros asuntos creo que no es necesario que te escriba más, pues por este paisano vuestro, un hombre sin duda excelen-

\footnotetext{
autem omnes, qui per angustiam concessi temporis interesse poteramus, et hujus Academiae sigillo publico obsignavimus. [...]

Has ad te literas quam brevissime scripsimus, ut angustiis temporis pareremus. A te vero magnopere contendimus, ne tuae erga nos familiaritatis consuetudinem jam incoeptam intermori sinas. Id si sedulo feceris, nos parem tibi gratiam refferre conabimur. Dominus Jesus tuos tuorumque fratrum pios conatus, Ecclesiae Christi incremento, quam diutissime fortunet". El propio Knox da cuenta de esta reunión en D. Laing (ed.), The History of the Reformation in Scotland. Edimburgo: the Wodrow Society, 1848, vol. II, p. 534.

38 Esta carta a Knox a la que Beza se refiere no se conserva.
} 
te, puedes enterarte mucho mejor que por mí mismo ${ }^{39}$. Así pues, quédate sólo con que todos nosotros seguimos bien por la gracia de Dios y que con la mayor concordia permanecemos exactamente en el mismo estado en que en su día nos dejaste. Es más, hasta tal punto ha crecido ahora nuestra pequeña universidad que creo que hay pocas más frecuentadas. [...]

Sobre los asuntos de Francia, en el momento en que te escribo esta carta todo se nos anuncia propicio, como sabrás por la propia persona que te la entrega. [...]

Para la última feria se publicaron mis lecciones Sobre la poligamia, los repudios y los divorcios ${ }^{40}$, que querría que leyeses y que sopeséis también allí vosotros. Así que te habría enviado con gusto algunos ejemplares, si no hubiera temido sobrecargar a este amigo nuestro, que sin embargo me ha prometido que llegará allí al menos con un ejemplar, con el favor de Dios. Me ha obligado además la maledicencia de ciertas personas muy molestas a publicar no sé qué tonterías, de las que te envío dos ejemplares: uno para ti, para que, cuando también quieras entretenerte con tonterías, te acuerdes en serio de tu querido Beza, y otro para el doctor Buchanan ${ }^{41}$, que ojalá esté allí con vosotros y con salud, y que querría que saludases también de mi parte, como viejo amigo suyo que soy ${ }^{42}$. Toda nuestra comunidad os envía a ti y a todos tus compañeros muchos saludos en el Señor, el cual es el autor y el garante de esta común unión nuestra. Yo en particular, querido hermano, te suplico que te acuerdes en tus oraciones constantemente de mí, muy desdichado pecador e inútil hombrecillo a quien Dios ha impuesto tan pesada carga, para que al menos pueda yo reconocer de algún modo mi culpa ante su tribunal; yo le ruego a Él a mi vez que te sostenga con su santo y poderoso Espíritu, junto con vuestro ilustre liberador, que tantas veces os ha sido preservado milagrosamente, a quien yo también saludo con la mayor humildad ${ }^{43}$. [...]

[Post data:] ¡Qué bien, querido hermano, habéis hecho al unir la disciplina con la doctrina! Te ruego y suplico que sigáis así, para que

39 Se desconoce la identidad del mensajero de esta carta.

40 Las obras a las que aquí se refiere son De polygamia (1568), y De repudiis (1569).

41 George Buchanan (1506-1582), poeta e historiador escocés.

$42 \mathrm{La}$ obra a la que se refiere es Poemata. Sobre esta obra, véase Thomas Thomson, "The Poemata of Théodore de Bèze", en I. D. McFarlane (ed.), Acta Conventus Neo-Latini Sanctandreani: Proceedings of the Fifth International Congress of Neo-Latin Studies. Binghamton, NY: Medieval \& Renaissance Texts \& Studies, 1986, pp. 409-415.

43 Se refiere a James Stewart (1531/2-1570), conde de Moray, regente de Escocia. 
no os pase lo mismo que a tantos que, al tropezar en el umbral, no pueden avanzar, es más, incluso a veces ni siquiera lo desean, algo que es con mucho lo más lamentable ${ }^{44}$.

En su posdata, Beza alude al hecho de que el 15 de diciembre de 1567, tras la caída de María Estuardo, el Parlamento de Escocia aprobara los acuerdos de reforma de 1560, por tanto imponiendo la confesión de fe. Frente a la situación de la iglesia anglicana, que tanto Beza como Knox consideran desastrosa, como ya Beza ha puesto de manifiesto en repetidas ocasiones en sus intercambios epistola-

44 Tomo X, 1569, eds. Claire Chimelli, Alain Dufour, Béatrice Nicollier-De Weck, Hippolyte Aubert, 1980, pp. 113-115: "Gratiam et pacem tibi, mi frater, omnibusque vestris sanctis Ecclesiis opto a Deo et patre Domini nostri Jesu Christi, cui etiam gratias ago assidue, tum de tanta ipsius in vos beneficentia, tum de vestra singulari in afferendo ipsius cultu constantia et animi fortitudine.

Caeterum quum honorificum illud et vere Christianum Academiae vestrae testimonium, quo nostrarum Ecclesiarum confessionem amplexi estis, mihi redditum esset, aliquot post mensibus et tibi privatim et aliis fratribus per literas significavi quam grata et quam jucunda nobis omnibus ipsisque, in primis Tigurinis fratribus fuerit vestra haec in omnibus nobiscum in Domino conjunctio, quam et confidimus fore sempiternam, et adversus ipsas inferorum portas firmam permansuram.

Quod autem ab eo tempore nullas a me acceperis, nolim te, mi frater, vel contemptui vel negligentiae, vel etiam ocupationibus tribuere, sed partim tabellariorum penuriae, quos sane nullos satis idoneos habui, partim etiam perpetuis horum temporum tempestatibus, a quibus etsi, singulari quodam Dei Opt. Max. beneficio, adhuc tuta fuit haec civitas, tamen quum et nobis valde sint, ut tu nosti, propinquae $[\ldots]$.

De rebus vero nostris $\|$ non est, opinor, necesse me ad te pluribus scribere, quum ex hoc vestrate, homine sane optimo, singula possis multo melius quam ex me ipso cognoscere. Tantum igitur haec habeto, valere adhuc nos omnes per Dei gratiam et in eo ipso statu concordibus prorsus animis perstare in quo tu nos olim reliquisti. Imo etiam ita nunc nostra haec Academiola excrevit, ut paucas esse frequentiores existimem. [...]

De rebus Gallicis, quo tempore haec ad te scribebam, omnia fausta nobis nuntiabantur, sicut ex hoc ipso cognosces a quo istas accepisti. [...]

Editae sunt superioribus nundinis meae quaedam praelectiones De polygamia, repudiis et divortiis, quas velim te legere, et a vobis istic quoque expendi. Itaque nonnulla earum exemplaria libenter ad te misissem, nisi essem veritus hunc nostrum gravare, qui tamen promisit se cum uno saltem exemplari istuc, Deo favente, perventurum. Coegit me praeterea quorundam importunissimorum hominum maledicentia, nescio quid nugarum edere, quarum exempla $\|$ duo ad te mitto; unum tibi, ut quum nugari etiam voles, Bezae tui serio recorderis; alterum D. Buchanano, quem istic esse et valere opto, ac etiam ex me, ut vetere amico, saluere. Universus noster coetus jubet te omnesque adeo collegas plurimum saluere in Domino, communi hujus nostrae conjunctionis authore ac vindice. Ego nominatim, mi frater, te precor ut mei miserrimi peccatoris et inutilis homunculi, cui tantum oneris Deus imposuit, assidue in tuis precibus memineris, ut culpam saltem praestare aliquo modo possim aliquando coram ipsius tribunali, quem vicissim rogo ut te sancto et potente Spiritu suo fulciat, una cum insigni illo vestro toties mirabiliter vobis conservato liberatore, quem ego quam humillime saluto. [...]

[P.D.] Euge mi frater, quam recte illud quod disciplinam simul cum doctrina conjungitis! Obsecro et obtestor ut ita pergatis, ne vobis idem quod tam multis eveniat ut, quia in limine impegerint, progredi non possint, imo etiam interdum ne velint quidem quod longe miserrimum est." 
res con Bullinger, la disposición de Escocia es prometedora, y abre la esperanza de que se contagie a Inglaterra. Para Beza es indudable que Knox es el pilar fundamental sobre el que se ha establecido y se sostiene en Escocia lo que a sus ojos es la fe verdadera. Así lo reconoce en la carta fechada el 12 de abril de 1572 (Carta 916) que Beza envía a Knox, en la que le felicita por la constancia en su trabajo por preservar los logros conseguidos en 1567, los cuales ya le había animado a conservar a toda costa en su carta anterior, de 1569:

Aunque estamos físicamente separados por tan gran espacio de tierras y del propio mar, querido Knox, sin embargo no dudo que entre nosotros siempre ha estado en vigor, y lo estará hasta el final, esa máxima unión espiritual, sancionada por el vínculo de un mismo espíritu y una misma fe. Y sin duda creo que vosotros pensáis muy a menudo en esta iglesia de Ginebra en particular, al igual que nosotros por nuestra parte guardamos continua memoria de vosotros ante el Señor; este mutuo y santísimo aliento común es prácticamente lo único que me sostiene en tan gran perturbación de los sucesos humanos, como creo que también a vosotros allí. [...] Deduzco que las iglesias de Escocia pertenecen a esa clase por argumentos muy seguros, pues en ellas no han podido corromper la pureza de la doctrina ni doblegar las reglas de la disciplina, descuidada por tantos pueblos, los ataques de Satanás, tan numerosos, grandes y constantes como creo que todavía no ha padecido en tan pocos años ningún pueblo. Bendito sea el Señor nuestro Dios que te ha obsequiado con esa constancia de ánimo y fortaleza a ti, querido hermano, que estás como al mando del timón, y a los demás remeros, superiores e inferiores. Es éste un gran regalo de Dios, que hayáis introducido en Escocia tanto la religión pura como el buen orden, a saber, la atadura que permite retener la doctrina. Así os suplico y os ruego: retened ambas cosas a la vez y acordaos de que, si perdéis una de las dos, la otra no puede permanecer para siempre. $[\ldots]$

Pero querría, querido Knox, que tú y los demás hermanos recordaseis también lo que se puede ver casi con los propios ojos: que, así como los obispos engendraron el papado, del mismo modo los pseudo-obispos-que son restos del papado-van a traer el epicureísmo a las tierras. Que se guarden de esta peste los que quieren que se salve la Iglesia, y, aunque por el momento en Escocia la estás derrotando, no la admitas nunca, por mucho que te la aconsejen lisonjeramente con el pretexto de mantener la unidad; este pretexto ha engañado a muchos antiguos y excelentes. 
Ahora sobre nuestras cosas. Mientras os atribulan allí tragedias tan grandes como las que ni siquiera toda Grecia ha conmemorado en sus teatros ${ }^{45}$, nosotros entre tanto hemos luchado contra la peste todos estos seis años $[\ldots]^{46}$. Pero bendito sea el Señor que así puso a prueba a los dos en el horno sin consumir a ninguno, y que haga que, castigados por estas varas de hierro, tengamos por fin mejores pensamientos. Sin duda nuestra ciudad no es la que viste. Los bancos de la universidad, tan concurridos hace no tan poco, están ahora vacíos. Desde dentro también nos atenaza duramente algún que otro mal. Pero todavía subsistimos, por la gracia de Dios, y mientras permanezca entero ese calor vital, es decir, la misma doctrina, el mismo buen orden y el mismo consenso entre los órdenes que los que había cuando estuviste aquí, no dudamos que, cuando en su momento recuperen todos los miembros de nuevo el vigor, el cuerpo entero se levantará. Así pues, ayudadnos con vuestras oraciones ante Dios, como también nosotros os tenemos presentes en nuestro corazón y acostumbramos a rezar continuamente por el estado del reino de Escocia y la salud de todos los buenos día y noche. Nos será grato si pudierais informarnos de vuestros asuntos con la mayor frecuencia posible. Lo mismo haremos por nuestra parte con mayor diligencia que nunca antes, puesto que parece que la paz de Francia nos ha despejado el camino para hacer eso mismo, por muy lejos que estemos.

Que tengas salud, varón ilustre y muy venerable hermano ${ }^{47}$.

45 Esto hace referencia a los enfrentamientos armados (en 1565, 1566, 1567 y 1570) entre las fuerzas de los partidarios de María Estuardo, a saber, católicos, y las de Isabel I de Inglaterra, protestantes.

46 Se refiere al periodo comprendido entre 1567 y 1573.

47 Tomo XIII, 1572, eds. Alain Dufour, Béatrice Nicollier-De Weck, Hippolyte Aubert, 1988, pp. 118-119: "Etsi tanto terrarum et maris ipsius intervallo disjuncti corporibus sumus, mi Cnoxe, tamen minime dubito quin inter nos semper viguerit et ad extremum vigeat summa illa animorum conjunctio, unius ejusdemque spiritus fideique vinculo sancita. Et vos certe existimo de hac praesertim Genevensi Ecclesia saepissime cogitare, ut nos vicissim vestri memoriam coram Domino perpetuam custodimus, quae mutua sanctissima $\sigma u \mu \pi v o i ́ \alpha$ ( $s i c$ ) pene me sola, et vos quoque istic, ut arbitror, in tanta rerum humanarum perturbatione sustentat. [...] Hujusmodi esse Scoticas Ecclesias certissimis argumentis colligo, in quibus neque doctrinae puritatem corrumpere, neque

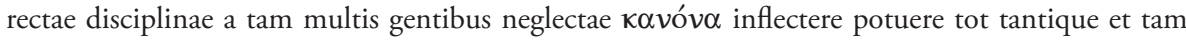
diuturni Sathanae insultus, quantos nullam adhuc gentem tam paucis annis sustinuisse existimo. Benedictus sit Dominus Deus noster, qui te, mi frater, veluti gubernaculis admotum, caeterosque remiges ac subremiges hac constantia et animi $\|$ fortitudine donavit. Magnum est hoc Dei munus, quod una et religionem puram et $\varepsilon \dot{v} \tau \alpha \xi i \alpha \nu$, doctrinae videlicet retinendae vinculum, in Scotiam intulistis. Sic obsecro et obtestor, haec duo simul retinete ut uno amisso, alterum diu permanere non posse semper memineritis. [...] 
Queda patente en la carta de Beza el miedo a que la Iglesia de Inglaterra ejerciera su influencia sobre Escocia, y que el anglicanismo, que Beza entiende como una forma de "epicureísmo" promovido por "pseudo-obispos", supervivientes de los tiempos del catolicismo, fuera admitido so pretexto del supuesto beneficio de establecer la unidad religiosa en la isla. Nuevamente, no se conserva la carta de respuesta de Knox a Beza. La siguiente vez que Beza menciona a Knox no lo hace dirigiéndose a él directamente, sino ya a Peter Young, en una carta del 17 de julio de 1573 (Carta 1007); no había más remedio, Knox había muerto en noviembre del año anterior. En esta carta a Young, Beza reitera su compromiso con los asuntos de Escocia y su apoyo a la iglesia escocesa, elogiando además a la figura de Knox:

Pero aunque nuestros cuerpos estén separados por un enorme espacio de tierras y mar, sin embargo tengo la esperanza y el pleno convencimiento de que nuestros ánimos están muy unidos, y de esta unión tengo como prenda la testificación, que nos enviasteis antaño desde allí, de nuestro común acuerdo con la confesión de Suiza, en la cual no dudo que permaneceremos hasta el final, del modo en que aquel bienaventurado Knox nuestro quiso como suscribir incluso con una carta suya, que conservo conmigo como un tesoro ${ }^{48}$.

Sed et istud, mi Cnoxe, te caeterosque fratres velim meminisse quod jam oculis pene ipsis observatur, sicut Episcopi Papatum pepererunt, ita pseudepiscopos (Papatus reliquias) Epicureismum terris invecturos. Hanc pestem caveant qui salvam Ecclesiam cupiunt, et quum illam in Scotia in tempore profligaris, ne, quaeso, illam unquam admittas, quantumvis unitatis retinendae specie quae veteres etiam optimos multos fefellit, blandiatur.

De rebus nostris. Dum vos istic exercent tragoediae quantas ne Graecia quidem tota suis theatris celebravit, nos interea totum hoc sexennium cum peste sumus luctati [...]. Sed benedictus Dominus qui sic utrosque in hac fornace exploravit, ut neutros consumpserit, faxitque ut his ferulis castigati tandem melius sapiamus. Urbs quidem $\|$ nostra non ea est quam vidisti. Subsellia scholae non ita pridem frequentissima, jam vacua sunt. Intus etiam unus et alter nos duriter exercuit. Sed adhuc subsistimus per Dei gratiam, et quum integer sit vitalis ille calor, eadem illa videlicet tum doctrina, tum $\varepsilon \dot{\tau} \tau \alpha \xi i ́ \alpha$, tum ordinum inter se consensio quam quum hic esses animadvertisti, non dubitamus quin suo vigore rursum membris omnibus suo tempore restituto, corpus universum erigatur. Adjuvate nos igitur vestris apud Deum precibus, ut et vos vicissim pectore circumferimus, et assidue pro Scotici regni statu bonorumque omnium salute precari dies ac noctes consuevimus. Gratum autem nobis erit si quam saepissime fieri poterit, de rebus vestris certiores nos feceritis. Idem vicissim apud vos faciemus multo quam unquam antea diligentius, quum Gallica pax nobis quantumvis longo intervallo dissitis aditum ad eam rem patefecisse videatur.

Bene vale, vir eximie, et frater plurimum observande."

48 Tomo XIV, 1573, eds. Alain Dufour, Béatrice Nicollier-De Weck, Hippolyte Aubert, 1990, p. 158: "Etsi vero ingenti terrarum et maris intervallo corpora nostra disjuncta sunt, spero tamen ac plane mihi persuadeo, nos esse animis conjunctissimos, cujus certissimum pignus habemus missam olim istinc ad nos communis cum Helvetica confessione consensus testificationem, in qua non dubito quin ad extremum permansuri simus, sicut beatus ille noster Cnoxius suis etiam literis, quas 
De nuevo, esta epístola se ha perdido. Un año después, el 12 de abril de 1574, Beza vuelve a escribir a Young (Carta 1060), y sus palabras apuntan a que su carta responde a una epístola de Young (también ahora perdida) en la que éste lamentaba el fallecimiento de Knox. Beza reitera lo desafortunado de la pérdida para la causa en Escocia:

Salud. Así pues, ¡también nuestro Knox, tan valeroso sufridor de Dios, nos ha sido arrebatado, querido Young! ¡Y cuántos y qué grandes hombres hemos perdido en estos pocos años, es más, en un solo día! Pero está bien que nos apoyemos en quien, muerto una sola vez por nosotros, vive ya y vivirá siempre para Dios-y ańado que también para nosotros- ${ }^{49}$.

Estas lamentaciones reaparecen en la carta, enviada por Beza ese mismo día, a la Iglesia de Escocia en general (Carta 1061):

Pues sin duda esta Iglesia no sólo os reconoce como a hermanos, sino que os abraza como una madre a sus hijos, pues se acuerda de aquellos grandes varones, el doctor Knox y el doctor Goodman, a los que tanto quiso, como merecían, y durante tanto tiempo abrigó en su regazo, hasta que regresaron con vosotros para construir aquella gran obra del Señor, felizmente, como muestra el resultado. [...] La muerte del doctor Knox, como era natural, nos causó un dolor enorme: en efecto, la muerte de los buenos siempre nos parece prematura, al ser tan grande la escasez de ellos. Sin embargo, aligera mucho ese muy justo pesar nuestro el hecho de que os dejara las iglesias establecidas de la mejor manera e incluso, según oímos, mucho más pacificadas que nunca antes, a vosotros que estáis perfectamente instruidos en la piedad y en la doctrina. Esperamos que siga siendo exactamente asi ${ }^{50}$.

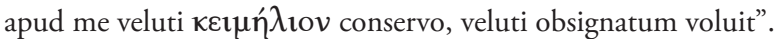

49 Tomo XV, 1574, eds. Alain Dufour, Béatrice Nicollier-De Weck, 1991, p. 70: "S. Ergo nobis etiam Knoxius ille noster fortissimus Dei athleta ereptus est, mi Juni! et quot quantosque homines istis paucis annis imo etiam uno die amisimus! Sed bene est quod eo uno nitimur qui semel pro nobis mortuus, jam Deo (addo etiam nobis) vivit, vivetque in aeternum".

50 Tomo XV, 1574, pp. 73-74: "Nam certe vos haec Ecclesia non modo pro fratribus agnoscit verum etiam quasi mater filios complectitur, memor videlicet magnorum illorum virorum D. Cnoxi et D. Gudmani quos sibi merito charissimos tantisper fovit in sinu dum ad vos redirent, magnum illud opus Domini feliciter ut exitus ostendit extructuri. [...] Ex D. Cnoxi morte maximum sicuti par est dolorem cepimus: est enim certe bonorum mors semper nobis immatura in tanta illorum penuria. Illud tamen justisimum $(\mathrm{sic})$ nostrum moerorem multum levit quod Ecclesias optime institutas atque etiam, ut audimus, multo quam unquam antea pacatiores vobis et 
El 26 de agosto de 1579, Beza escribe a Peter Young una carta (Carta 1367) pidiéndole que le envíe "al menos una imagen del doctor Knox, si queda alguna, y también de otros que haya dignos de eterno recuerdo, junto con una breve narración de los hechos notables llevados a cabo por ellos" ${ }^{\text {. }}$. Beza añade, en caso de que "no hubiera ninguna imagen de él hecha por pintores", que Young le describiese "de algún modo su rostro y su porte, tal y como era alli" 52 . En efecto Beza llevaba preparando su obra Icones id est verae imagines virorum doctrina simul et pietate illustrium desde 1577; su idea era escribir dos volúmenes, uno dedicado a teólogos, y otro a príncipes y magistrados que, en palabras de Beza, "fueron señalados instrumentos de Dios para comenzar o alentar la restauración de las Iglesias" "53. El primer volumen, dedicado a Jacobo VI de Escocia, vio la luz en latín (1580) y en francés (1581), y del segundo se publicó una edición en 1673 con algunos retratos. En su respuesta del 13 de noviembre de ese año (Carta 1385), Young se disculpa ante Beza por no poder facilitarle ningún retrato de Knox:

En cuanto a lo que me pides de que te envíe retratos de los varones ilustres que se esforzaron por hacer avanzar entre nosotros la gloria de Dios, en particular del doctor Knox, te respondo: siempre fue una dejadez de nuestro pueblo, por no decir algo más grave, el no preocuparse nunca nada por eso. Por ello sucede que ni siquiera de Knox, un varón muy digno de eterna memoria, queda ningún retrato. Sin embargo he ido a buscar a nuestros pintores, y, si ellos cumplen su promesa, recibirás con esta carta un retrato suyo. Entre tanto, te describiré su rostro y su porte con mi pluma de la manera que pueda, en cuanto he podido recordar yo mismo, así como por el relato de personas muy allegadas a él mientras vivió, a las que he pedido su colaboración para esto. [...]

Pues bien, la estatura de su cuerpo fue un poco más baja que la justa, con una disposición de los miembros elegante y adecuada, de hombros anchos, dedos un poquito largos, cabeza pequeña, cabello negro, tez oscura y no desagradable de ver. En su rostro, grave y

pietate et doctrina instructissimis, reliquit. / Sic futurum omnino speramus".

51 Tomo XX, 1579, eds. Reinhard Bodenmann, Alain Dufour, Béatrice Nicollier-De Weck, Hippolyte Aubert, 1998, p. 173: "ac igitur, si fieri potest, ut saltem D. Knoxi imaginem, si qua extat, nancisci possim, et aliorum etiam, si qui sunt aeterna commemoratione digni, adjecta brevi insignium ab ipsis rerum gestarum narratione".

52 Tomo XX, 1579, p. 173: "Quod si etiam nulla sit ipsius effigies a pictoribus expressa, tu mihi utcunque illius vultum et habitum, qualis istic erat, describas velim, quo beneficio plurimum me tibi devinxeris".

53 Tomo XX, 1579, p. 173: "fuerunt insignia Dei organa ad inchoandam aut promovendam Ecclesiarum instaurationem". 
sereno, residían no sin cierta gracia una dignidad y majestad naturales, y en los momentos de ira la autoridad no se ausentaba de su ceño. Bajo su frente, un poco estrecha, crecía ligeramente un entrecejo poblado, las mejillas eran rosadas y algo henchidas, de forma que los ojos parecían remetidos y algo cóncavos. El color de éstos era de un azulado oscuro, su aspecto agudo y vívido, la cara más bien alargada, la nariz más bien grande, la boca amplia, los labios grandes y el superior un poco más grueso, la barba negra, ribeteada de canas, un palmo y medio de larga y moderadamente densa. Murió a los cincuenta y nueve ańos. [...].

Te envío el elogio del doctor Buchanan, muy venerable padre mío, junto con su retrato, pintado al vivo. [...]

Cuando estaba firmando estas palabras vino justo a tiempo el pintor, que me ha traído pintados en una cajita los retratos de Buchanan y Knox juntos ${ }^{54}$.

Sin embargo, el retrato de Knox no llegó a tiempo para que fuese incluido en la edición de 1580 de Icones, en la que se utiliza para dar rostro a Knox el retrato de un hombre desconocido; la edición de 1581 sí que incluye, no obstante, el auténtico retrato de $\mathrm{Knox}^{55}$. Beza dedica la edición de 1580, como ya se ha mencionado, a Jacobo VI de Escocia, al que elogia ("la fama de tu singular piedad ha alcanzado estas tierras remotas") ${ }^{56}$, y al que recuerda "el beneficio aportado al reino

54 Tomo XX, 1579, p. 243: "Quod petis ut ad te illustrium virorum qui in promovenda Dei gloria apud nos desudarunt, praesertim D. Cnoxi, imagines mittam, sic habeto: eam semper fuisse nostrae gentis incuriam, ne quid gravius dicam, ut nihil unquam huic studio tribuerit. Quo fit ut ne Cnoxi quidem, viri sempiterna memoria dignissimi, effigies ulla extet. Adii tamen pictores nostros, qui si modo pollicitis steterint, una cum hisce imaginem ejus accipies. Interim ego hic tibi ejus vultum ac habitum meo penicillo quantum vel ipse meminisse, vel ex ipsius familiarissimorum dum vixit relatu (quos in consilium super hac re adhibui), consequi potui, utcunque describam. [...] Fuit itaque statura corporis paulo justa minor, apta et eleganti membrorum compositione, humeris latioribus, digitis longiusculis, / caput modicum, capillus niger, facies subnigricans nec aspectu ingrata. In vultu gravi et severo inerat non sine gratia quadam dignitas et majestas naturalis, nec aberat in ira supercilio autoritas. Sub fronte angustiore modice assurgebat superciliorum vallum, malis etiam subrubris ac leviter tumentibus, quo fiebat ut oculi retrocedere et cavi viderentur. Color eis erat in fusco caeruleus, aspectos acer et vividus, facies longiuscula, nasus longior, ore amplo, labris magnis ac superiore paulo crassiore, barba nigra variantibus eam canis sesquipalmum longa ac modice densa. Decessit undesexagesimo aetatis anno. [...] D. Buchanani patris mei observandissimi elogium ad te mitto una cum ipsius effigie ad vivum expressa. [...]

Quum hasce obsignarem, commodum advenit pictor, qui mihi una pyxide Buchananum et Cnoxum simul expressos attulit".

55 C. Borgeaud, "Le vrai portrait de Knox", en Bulletin de la Societe de l'Histoire du Protestantisme Français, 84 (1935), pp. 11-36.

56 Tomo XXI, 1580, eds. Alain Dufour, Hervé Genton, Béatrice Nicollier-De Weck, Hippolyte Aubert, Reinhard Bodenmann, 1999, p. 45: "ad extremas usque terras hujus tuae singularis 
de Escocia por el ministerio de dos varones enormes, el doctor Knox, escocés, y el doctor Christopher Goodman, inglés" ${ }^{5}$. Beza insiste en que "las iglesias de Escocia están unidas a la de Ginebra por cierto vínculo especial consistente no sólo en la confesión común, sino también en el buen orden eclesiástico" ${ }^{58}$. En una carta fechada el 16 de marzo de 1580 (Carta 1408), Beza acusa recibo de "las imágenes del doctor Knox y el doctor Buchanan, con la adición de los elogios de ambos,

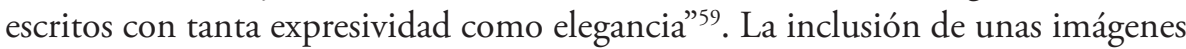
de este tipo en un contexto iconoclasta como el calvinista no quedó inadvertida, y Beza hubo de enfrentarse a críticas por ello ${ }^{60}$. El que Beza comenzara a trabajar en Icones a finales de la década de 1570 puede entenderse como una manera de gestionar el fallecimiento de tantos líderes de iglesias reformadas que habían sido compañeros de lucha: si Knox muere en 1572, Pierre Toussain muere en 1573, Joachim Camerarius en 1574, Bullinger en 1575, y Josiah Simler en 1576; tras la publicación de la obra, lo harían también Buchanan, en 1582, Zacharias Ursinus, en 1583, Rudolf Gwalther, en 1586, y Caspar Olevianus, en $1587^{61}$. Como lo hiciera Knox respecto de Escocia hacia el final de sus días, Beza asimismo llora en sus últimos años lo que entiende es la decadencia de una edad dorada, en su caso, en Ginebra: la situación actual, dice en Sermons sur le Cantique des Cantiques (1586), y en diversas cartas a correspondientes varios ${ }^{62}$, poco se parece a la que se vivía en tiempos de Calvino. Muerta su red de contactos, las esperanzas de juventud en una triunfal reforma paneuropea parecían finalmente dar al traste.

pietatis fama permanarit”.

57 Tomo XXI, 1580, eds. Alain Dufour, Hervé Genton, Béatrice Nicollier-De Weck, Hippolyte Aubert, Reinhard Bodenmann, 1999, p. 45: "haec Ecclesia partem sibi vendicet non poenitendam beneficii in Scotiae regnum maximorum virorum D. Joannis Cnoxi Scoti et D. Christophori Gudmanni Angli”.

58 Tomo XXI, 1580, pp. 45-46: "peculiari quodam communis non modo confessionis, verum

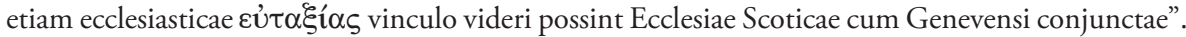

59 Tomo XXI, 1580, pp. 72-73: "D. Cnoxii et D. Buchanani imaginibus, additis etiam utriusque luculenter simul et eleganter descriptis elogiis".

60 C. Chazalon, "Théodore de Bèze et les ateliers de Laon", en Irena Backus et al. (eds), Théodore de Bèze (1519-1605): Actes du Colloque de Genève (septembre 2005). Ginebra: Droz, 2007, pp. 69-87 (véanse, específicamente, pp. 74-76). En la p. 87 se reproducen los retratos de Knox y Beza en las tres ediciones de Icones.

$61 \mathrm{La}$ muerte de todos estos líderes de la Reforma en tan poco tiempo ha sido descrita como "an emerging crisis of leadership in the Reformed churches", que resultó especialmente inquietante para Beza. Scott M. Manetsch, Theodore Beza and the Quest for Peace in France, 1572-1598. Leiden, Boston: Brill, 2000, p. 138.

62 Manetsch, Theodore Beza and the Quest for Peace, pp. 141-143. 